ORIGINAL RESEARCH

\title{
A Sex-Specific Analysis of Nutrition Label Use and Health, Douglas County, Nebraska, 2013
}

\author{
Dejun Su, PhD; Junmin Zhou, MD; Hannah L. Jackson, PhD, MPH; \\ Ghada A. Soliman, MD, PhD, RD; Terry T-K Huang, PhD, MPH; Amy L. Yaroch, PhD
}

\begin{abstract}
Suggested citation for this article: Su D, Zhou J, Jackson HL, Soliman GA, Huang TT, Yaroch AL. A Sex-Specific Analysis of Nutrition Label Use and Health, Douglas County, Nebraska, 2013. Prev Chronic Dis 2015;12:150167. DOI: http://dx.doi.org/ $10.5888 / \mathrm{pcd} 12.150167$.
\end{abstract}

\section{PEER REVIEWED}

\section{Abstract}

\section{Introduction}

In 2014 the US Food and Drug Administration proposed a series of changes to its 1992 guidelines on nutrition facts labeling to help consumers make informed food choices. To date, few studies have examined the association between consumers' use of the nutrition label and health. The objective of this study was to assess the association between nutrition label use and health and to determine whether the association differs by sex.

\section{Methods}

Using data from a population-based, random sample survey of 1,503 participants conducted in Nebraska in 2013, we performed $\chi^{2}$ tests to examine bivariate associations between selected health variables and nutrition label use, followed by logistic regression analysis to estimate these associations in a multivariate framework.

\section{Results}

A U-shaped relationship between self-rated health (SRH) and nutrition label use was observed. Both excellent and poor SRH were associated with a higher likelihood of nutrition label use than the 3 SRH categories in between. Being obese or having 1 of 4 chronic conditions (hypertension, diabetes, heart disease, high cholesterol) were both associated with higher odds of nutrition label use (odds ratio $[\mathrm{OR}]=2.63, P<.001 ; \mathrm{OR}=1.71, P<.05$, respectively) among men. These associations, however, were not significant among women.

\section{Conclusion}

A close association existed between health and nutritional label use. This association was more pronounced among men than among women. Nutrition education may benefit from factoring in the association between health and use of nutrition labels and the differences in these associations by sex.

\section{Introduction}

The 1990 Nutrition Labeling and Education Act mandated that standardized nutrition information appear on all packaged foods (1). In 2014, the US Food and Drug Administration (FDA) proposed a series of changes to the 1990 guidelines to help consumers make informed food choices to support healthy eating and lifestyles. The changes aimed to improve consumers' understanding of nutrition and food science, updated serving size requirements, and changed the design of the label (2). Although it is too soon to tell if the changes are accomplishing what FDA intended, findings from numerous studies have consistently shown that reading a nutrition label is associated with healthy food choices (3-7).

Consumers may use nutrition labels for different reasons. Some may use the nutrition information to aid in the consumption of more healthful foods and overall chronic disease prevention, whereas others may have chronic diseases and have been advised by their doctors to follow certain nutrition or dietary guidelines (8-10). Few studies to date have assessed the association between nutrition label use and health. Identifying this association and the factors contributing to label use could lead to a better understanding of the impact of nutrition labels on food choices among people with various health needs. 
In this study, we analyzed data from a population-based survey to assess whether nutrition label use was associated with health among adults in Douglas County, Nebraska (Omaha area), and how it was associated. Because previous literature suggested that women were more likely to read nutrition labels than men $(11,12)$, we sought to explore the association between health and nutrition label use for each sex. Men have a higher risk of cardiovascular diseases and associated death than women (13-19), and diet is a factor in preventing and treating cardiovascular diseases. We examined 4 hypotheses: 1) that a U-shaped relationship exists between self-rated health and nutrition label use such that excellent and poor health are both associated with a high likelihood of nutrition label use relative to health categories in between (very good, good, fair); 2) that being obese is related to a higher probability of using nutrition labels relative to being nonobese; 3) that having a chronic disease is positively related to nutrition label use; and 4) that substantial sex differences exist in the association between health and use of nutrition labels.

\section{Methods}

\section{Data}

Data for this study were from the Douglas County Community Health Survey, a population-based telephone survey conducted in the summer of 2013. The survey's target population was residents aged 18 years or older in Douglas County, the largest and most demographically diverse county in Nebraska with a 2013 estimated population of 524,697, of which approximately $11 \%$ were Hispanic, and 11\% African American. Another factor in selection of Douglas County was its proximity to the research and survey teams. The sampling frame of the survey was based on telephone numbers generated through the Genesys Sampling Systems, 2013 version (Marketing Systems Group), providing a comprehensive coverage of both landline and cellular telephones eligible for the survey with an oversampling of minority and rural residents. The use of standard random-digit dialing and computer-assisted telephone interviewing technique made it possible for the survey to generate a probability sample in which analytical results could be generalized to the study area. Altogether 1,503 participants (729 men and 774 women) completed the survey in either English $(95.3 \%)$ or Spanish $(4.7 \%)$. The overall response rate, combining both landline and cellular telephone interviews, was $39.8 \%$. The data were weighted using a 3-step process of calculating design weights, adjusting for nonresponse, and then raking to match the sample to population totals. This study was approved by the institutional review board of University of Nebraska Medical Center. Informed consent was obtained from each participant before administering the survey.

\section{Measures}

Nutrition label use was assessed with the following question: "Do you pay attention to information about sodium, fat, calories, or the use of preservatives when you purchase food?" Participants were given 5 possible responses: 1) always, 2) usually, 3) sometimes, 4) rarely, 5) never. The responses were further dichotomized into 2 categories: 1) usually not (sometimes, rarely, and never), and 2) usually do (all other responses).

In our analysis we examined the use of nutrition labels in relation to 5 variables: health status, demographics, socioeconomic status (SES), health behavior, and health care access. Health status variables were self-rated health (excellent, very good, good, fair, or poor), obesity (body mass index $[\mathrm{BMI}] \geq 30$ ), self-reported weight change in the past year (no change, gained weight, and lost weight), and measures on chronic conditions (whether the participant had ever been told by a doctor he or she had 1 of 4 diseases: hypertension, heart disease, diabetes, or high cholesterol). We also created a dummy variable with 1 indicating having at least 1 or more of the 4 chronic conditions, and 0 indicating having none.

Variables on demographics and SES were age, sex, marital status (married vs unmarried), race/ethnicity (non-Hispanic white, black, Hispanic, or other) country of birth (United States vs other), employment (employed vs unemployed), and education. All variables were based on self-report.

Health behavior and lifestyle variables were measured by smoking status (smoked at least 100 cigarettes in your life or never smoked), alcohol consumption (consumed alcohol in the past 30 days or not), leisure-time physical activity, number of meals eaten at fast food restaurants per week (continuous variable), and dietary preference (prefer meat or vegetables/fruits or no preference). Health care access was defined as having health insurance coverage and having at least 1 personal doctor.

\section{Statistical analysis}

We conducted bivariate cross-tabulations to assess the association between nutrition label use and selected health indicators. We used $\chi^{2}$ statistics and related $P$ values to determine whether associations were significant. We then conducted 3 logistic regression analyses in which we examined the relationship between nutrition label use and health indicators after controlling for selected variables on demographics, SES, health behaviors, and other selected variables of the whole sample, and of males and females. All analyses were conducted with the weighted sample in SPSS, version 21 (IBM Corp).

The opinions expressed by authors contributing to this journal do not necessarily reflect the opinions of the U.S. Department of Health and Human Services, the Public Health Service, the Centers for Disease Control and Prevention, or the authors' affiliated institutions. 


\section{Results}

\section{Differences by sex}

Several differences between men and women were significant (Table 1). Men were less likely to use nutrition labels than were women $(40.7 \%$ vs $54.3 \%, P<.001)$. Men were also less likely than women to report having gained weight over the past year $(15.9 \%$ vs $29.1 \%, P<.001)$ ). The proportion of male respondents who were employed was higher than the proportion of women $(72.7 \%$ vs $61.6 \%, P<.001)$. Men were less likely than women to report having at least 1 personal doctor $(69.5 \%$ vs $81.2 \%, P<.001)$.

Diet patterns also differed between men and women; men reported a higher frequency of fast-food consumption than did women ( 2.8 vs 1.8 times per week, $P<.001$ ). In addition, men were more likely to report a preference for meat than women $(38.8 \%$ vs $18.1 \%)$. By contrast, women were more likely to prefer fruits and vegetables than men $(33.2 \%$ vs $14.1 \%, P<.001)$.

\section{Bivariate associations}

Overall, bivariate associations between health and nutrition label use were more pronounced among men than women (Table 2). For example, although having hypertension was significantly associated with a higher use of nutrition labels among men $\left(\chi^{2}=18.53, P\right.$ $<.001)$, this association was not significant among female respondents. Similar differences between men and women were also observed for reported diabetes and high cholesterol.

Among men with heart disease, $67.7 \%$ reported nutrition label use compared with $38.3 \%$ of men without heart disease $\left(\chi^{2}=20.38, P\right.$ $<.001)$. The corresponding percentages among females were $71.4 \%$ and $52.9 \%$, respectively $(P<.05)$. Obese males reported more nutrition label use (50.7\%) compared with nonobese males $(37.4 \%)(P<.01)$. The opposite was shown for females: $50.7 \%$ of obese females and $57.5 \%$ of nonobese females $(P<.10)$ reported nutrition label use.

Results indicated a U-shaped relationship between self-reported health status and nutrition label use among both men and women. For both men and women, self-reported poor and excellent health were both associated with higher likelihood of nutrition label use compared with other self-rated health categories $(P<.001)$.

Respondents who reported changes in body weight during the previous year were more likely to have higher nutrition label use than those who reported no change since the previous year $(P<.001)$.
Notably, losing weight was associated with the highest nutrition label use. Among women, $67.9 \%$ of those who lost weight reported nutrition label use as compared with $45.5 \%$ among their counterparts who did not experience weight change. Similar findings were observed among men.

\section{Multivariate analyses}

We used a multivariate model to assess the relationship between health and nutrition label use, controlling for sociodemographic factors, health behaviors, and health care access (Table 3). The bivariate U-shaped relationship of the association between SRH and nutrition label use was confirmed in multivariate analysis. However, relative to what was found among women, this association was more significant among the entire sample and among men. For example, men who reported excellent health had higher odds of using nutrition labels than those who reported very good health $(54 \%$ lower $[P<.01])$ and good health $(60 \%$ lower $[P<$ $.01])$. The corresponding effect among women, however, was not significant.

Similar findings were also observed for obese respondents and for respondents with at least 1 of 4 chronic conditions (hypertension, heart disease, diabetes, or high cholesterol). In the total sample, obesity was associated with a higher nutrition label use (odds ratio $[\mathrm{OR}]=1.81 ; P<.001)$. This association was even more evident among men $(\mathrm{OR}=2.63 ; P<.001)$. By contrast, the corresponding association among women was not significant. We also found that although having at least 1 of the 4 chronic conditions considered was associated with higher nutrition label use among men $(\mathrm{OR}=1.71 ; P<.05)$, the association was not significant among women. Relative to those who did not experience weight change since last year, respondents who lost weight during the past year had higher odds of nutrition label use $(\mathrm{OR}=2.72 ; P<$ $.001)$, followed by those who gained weight $(\mathrm{OR}=1.69, P<.01)$. A similar association was observed among women. However, the corresponding association was less pronounced among men where gaining weight was not significantly associated with nutrition label use.

Findings also indicated associations between certain demographic characteristics and nutrition label use. In general, the probability of label reading increased with age, especially for women $(\mathrm{OR}=$ $1.02 ; 95 \%$ confidence interval $[\mathrm{CI}], 1.01-1.04 ; P<.01$ ). (We treated the variable age as continuous, so for every 1 year increase in age, we expected to see about a $2 \%$ increase in the odds of label reading.) Being married was associated with a higher probabil-

The opinions expressed by authors contributing to this journal do not necessarily reflect the opinions of the U.S. Department of Health and Human Services, the Public Health Service, the Centers for Disease Control and Prevention, or the authors' affiliated institutions. 
ity of label reading than being unmarried in the total sample as well as among women $(P<.05$ in both cases $)$. Country of birth was linked to label reading in the total sample. Immigrants were less likely than US-born respondents to read nutrition labels $(\mathrm{OR}=$ $0.51 ; 95 \%$ CI, 0.29-0.90, $P<.05)$.

SES was associated with nutrition label use in the total sample and among women. Being employed was associated with a higher probability of label use in the whole sample $(\mathrm{OR}=1.39 ; 95 \% \mathrm{CI}$, $1.02-1.90, P<.05)$ but was not significant for men. Similarly, having a college education or more was associated with the highest odds of label use in the total sample and among women ( $P$ $<.001$ in both cases), but the effect was not significant among men.

We found a substantial difference between sexes in the association between leisure-time physical activity and label use. Among men, the odds for those who had leisure-time physical activity to read labels were much higher compared with those reporting no leisure-time physical exercise $(\mathrm{OR}=3.22$; 95\% CI, 1.64-6.32, $P<$ $.01)$. This association, however, was not observed in women.

Dietary pattern and preference was significantly associated with nutrition label use among both men and women. The number of fast food meals consumed each week was negatively associated with the nutrition label use $(P<.01$ for both men and women). Compared with respondents who preferred meat in their diet, respondents who expressed a preference for fruits and vegetables were more likely to use nutrition labels, both men $(\mathrm{OR}=4.88 ; P<$ $.001)$ and women $(\mathrm{OR}=6.08 ; P<.001)$. One notable difference was that among women only, expressing no preference between meat and fruits and vegetables turned out to be associated with higher nutrition label use than expressing preference for meat (OR $=1.85 ; P<.05)$.

Although we did not observe a significant association between health insurance coverage and nutrition label use, we did observe an association between having at least 1 personal doctor or not with label reading among men. Men who had at least 1 personal doctor were more likely than men who had no personal doctor to read labels is significantly higher $(\mathrm{OR}=1.85 ; P<.05)$. The association, however, was not observed among women in the sample.

\section{Discussion}

This study assessed correlates of nutrition label use and how these correlates differ for men and women in a random sample of residents in Douglas County, Nebraska. Overall, the results indicated a close association between nutrition label use, health outcomes, and health behavior. We observed a U-shaped relationship between SRH and nutrition label use; excellent and poor SRH were both associated with a higher odds of nutrition label use than the $3 \mathrm{SRH}$ categories between them. Nutrition label use was also associated with leisure-time physical activity and preference for vegetables and fruits. Despite this general pattern, the association between health and nutrition label use was more pronounced among men than among women. Being obese or having one of the 4 chronic conditions considered (hypertension, heart disease, diabetes, high cholesterol) were both associated with higher odds of nutrition label use among men. These associations, however, were not significant among females.

These findings highlight important differences between the sexes in use of nutrition labels and plausible factors contributing to the differences. Consistent with related findings from previous studies $(11,12)$, women were more likely than men to report nutrition label use when purchasing food. One explanation is that traditional gender roles might encourage women to be meticulous about food selection for the whole family (20). However, the 2 groups might be using nutrition labels for different reasons. The closer linkages between health and nutrition label use among men may be suggestive of unique medical needs of men. This can be partially corroborated by our observation that men who had at least 1 personal doctor were more likely to read nutrition labels than those who did not. By contrast, women were more likely than men to be dissatisfied with body image and to have stronger motivation to change body weight by modifying their diet $(21,22)$. Our findings indicated that for both men and women, weight change since the previous year, relative to no change, was associated with higher odds of nutrition label use; however, this association seems more pronounced among women than among men. This partially explains why obesity was associated with nutrition label use only among men, but not among women, once the effect of body weight change had been taken into account. Similar findings were also reported among adolescents where results indicated that reading nutrition labels was associated with higher fat intake among boys, but not among girls (23).

An implication of these findings is that nutrition education efforts may need to be tailored to specific populations (eg, men vs women, younger vs older) and to modes of delivery. For instance, the strong association between chronic conditions and nutrition label use among men tends to suggest that the clinical setting might be a potential place to disseminate targeted nutrition education for men. Similarly, other potential settings to disseminate this type of information to men can include gymnasiums and parks, given the close association between physical exercises and nutrition label use among males.

The opinions expressed by authors contributing to this journal do not necessarily reflect the opinions of the U.S. Department of Health and Human Services, the Public Health Service, the Centers for Disease Control and Prevention, or the authors' affiliated institutions. 
This study has several limitations. First, the use of cross-sectional data made it difficult for us to infer causality. Second, the survey data we used contained no qualitative data on nutrition label use such as the purpose of reading the label, perceived usefulness of the label, and how label use impacts dietary behavior. Moreover, the survey question on nutrition label use concerned only sodium, calories, fat, or use of preservatives and did not cover all nutrition elements. Third, the use of self-reported data can potentially incur recall bias especially for variables based on respondents' long-term memory, such as changes in body weight since the previous year. Some of the question items in the survey were not tested for reliability and validity. Finally, this study was based on a regional sample in Nebraska, which limits generalizability of our findings to other regions.

Despite these limitations, this population-based study is unique in that it assessed the less-examined associations between nutrition label use and health status, especially exploring differences among men versus women. These findings add to the extant body of literature on differences between men and women in health behaviors and reinforce justifications for sex-specific nutrition education (24). Future studies could confirm these findings in a large, nationally representative sample and explore how tailored interventions could be developed to increase nutrition label use and improve dietary patterns across various populations.

\section{Acknowledgments}

This study was based on data collected by the Center for Reducing Health Disparities at the University of Nebraska Medical Center. We thank Romeo Guerra, Larry Andelt, and Harlan Sayles for their input in the data collection and preparation process. All authors have no conflict of interest or any financial disclosure to declare in preparation of this article.

\section{Author Information}

Corresponding Author: Dejun Su, PhD, Department of Health Promotion, Social and Behavioral Health, College of Public Health, University of Nebraska Medical Center, Omaha, NE 68198-4340. Telephone: 402-552-2359. Email: dejun.su@unmc.edu.

Author Affiliations: Junmin Zhou, Hannah L. Jackson, Ghada A. Soliman, University of Nebraska Medical Center, Omaha, Nebraska; Terry T-K Huang, University of Nebraska Medical Center and City University of New York, New York, New York; Amy L. Yaroch, University of Nebraska Medical Center and Gretchen Swanson Center for Nutrition, Omaha, Nebraska.

\section{References}

1. Nutrition Labeling and Education Act of 1990, Pub. L. No. 101-535, (November 5), 104 Stat. 2355 (November 5, 1990).

2. US Department of Health and Human Services, U.S. Food and Drug Administration. Proposed changes to the nutrition facts label; 2014. http://www.fda.gov/Food/GuidanceRegulation/ GuidanceDocumentsRegulatoryInformation/LabelingNutrition/ ucm385663.htm. Accessed November 28, 2014.

3. Barreiro-Hurlé J, Gracia A, de-Magistris T. Does nutrition information on food products lead to healthier food choices? Food Policy 2010;35(3):221-9.

4. Kreuter MW, Brennan LK, Scharff DP, Lukwago SN. Do nutrition label readers eat healthier diets? Behavioral correlates of adults' use of food labels. Am J Prev Med 1997; 13(4):277-83.

5. Ollberding NJ, Wolf RL, Contento I. Food label use and its relation to dietary intake among US adults. J Am Diet Assoc 2011;111(5,Suppl):S47-51.

6. Variyam JN. Do nutrition labels improve dietary outcomes? Health Econ 2008;17(6):695-708.

7. Wojcicki JM, Heyman MB. Use of food labels, awareness of nutritional programmes and participation in the special supplemental program for Women, Infants and Children (WIC): results from the National Health and Nutrition Examination Survey (2005-2006). Matern Child Nutr 2013; 9(3):299-308.

8. American Heart Association Nutrition Committee; Lichtenstein AH, Appel LJ, Brands M, Carnethon M, Daniels $\mathrm{S}$, Franch HA, et al. Diet and lifestyle recommendations revision 2006: a scientific statement from the American Heart Association Nutrition Committee. Circulation 2006; 114(1):82-96.

9. Hu FB, Willett WC. Optimal diets for prevention of coronary heart disease. JAMA 2002;288(20):2569-78.

10. Meigs JB, Stafford RS. Cardiovascular disease prevention practices by US Physicians for patients with diabetes. J Gen Intern Med 2000;15(4):220-8.

11. Satia JA, Galanko JA, Neuhouser ML. Food nutrition label use is associated with demographic, behavioral, and psychosocial factors and dietary intake among African Americans in North Carolina. J Am Diet Assoc 2005;105(3):392-402, discussion 402-3.

12. Rasberry CN, Chaney BH, Housman JM, Misra R, Miller PJ. Determinants of nutrition label use among college students. Am J Health Educ 2007;38(2):76-82.

The opinions expressed by authors contributing to this journal do not necessarily reflect the opinions of the U.S. Department of Health and Human Services, the Public Health Service, the Centers for Disease Control and Prevention, or the authors' affiliated institutions. 
13. Crimmins EM, Kim JK, Solé-Auró A. Gender differences in health: results from SHARE, ELSA and HRS. Eur J Public Health 2011;21(1):81-91.

14. Kalyani RR, Lazo M, Ouyang P, Turkbey E, Chevalier K, Brancati $F$, et al. Sex differences in diabetes and risk of incident coronary artery disease in healthy young and middleaged adults. Diabetes Care 2014;37(3):830-8.

15. Wannamethee SG, Papacosta O, Lawlor DA, Whincup PH, Lowe GD, Ebrahim S, et al. Do women exhibit greater differences in established and novel risk factors between diabetes and non-diabetes than men? The British Regional Heart Study and British Women's Heart Health Study. Diabetologia 2012;55(1):80-7.

16. Mendelsohn ME, Karas RH. Molecular and cellular basis of cardiovascular gender differences. Science 2005; 308(5728):1583-7.

17. Barrett-Connor E. Sex differences in coronary heart disease. Why are women so superior? The 1995 Ancel Keys Lecture. Circulation 1997;95(1):252-64.

18. Mosca L, Barrett-Connor E, Wenger NK. Sex/gender differences in cardiovascular disease prevention: what a difference a decade makes. Circulation 2011;124(19):2145-54.

19. Nikiforov SV, Mamaev VB. The development of sex differences in cardiovascular disease mortality: a historical perspective. Am J Public Health 1998;88(9):1348-53.

20. Guthrie JF, Fox JJ, Cleveland LE, Welsh S. Who uses nutrition labeling, and what effects does label use have on diet quality? J Nutr Educ 1995;27(4):163-72.

21. Demarest J, Allen R. Body image: gender, ethnic, and age differences. J Soc Psychol 2000;140(4):465-72.

22. Gross SM, Gary TL, Browne DC, LaVeist TA. Gender differences in body image and health perceptions among graduating seniors from a historically black college. J Natl Med Assoc 2005;97(12):1608-19.

23. Huang TT, Kaur H, McCarter KS, Nazir N, Choi WS, Ahluwalia JS. Reading nutrition labels and fat consumption in adolescents. J Adolesc Health 2004;35(5):399-401.

24. Stran KA, Knol LL. Determinants of food label use differ by sex. J Acad Nutr Diet 2013;113(5):673-9.

\footnotetext{
The opinions expressed by authors contributing to this journal do not necessarily reflect the opinions of the U.S. Department of Health and Human Services, the Public Health Service, the Centers for Disease Control and Prevention, or the authors' affiliated institutions.
} 


\section{Tables}

Table 1. Variables Used in Analysis of Nutrition Label Use and Health in a Sample $(N=1,503)$ of Men and Women, Douglas County, Nebraska, 2013

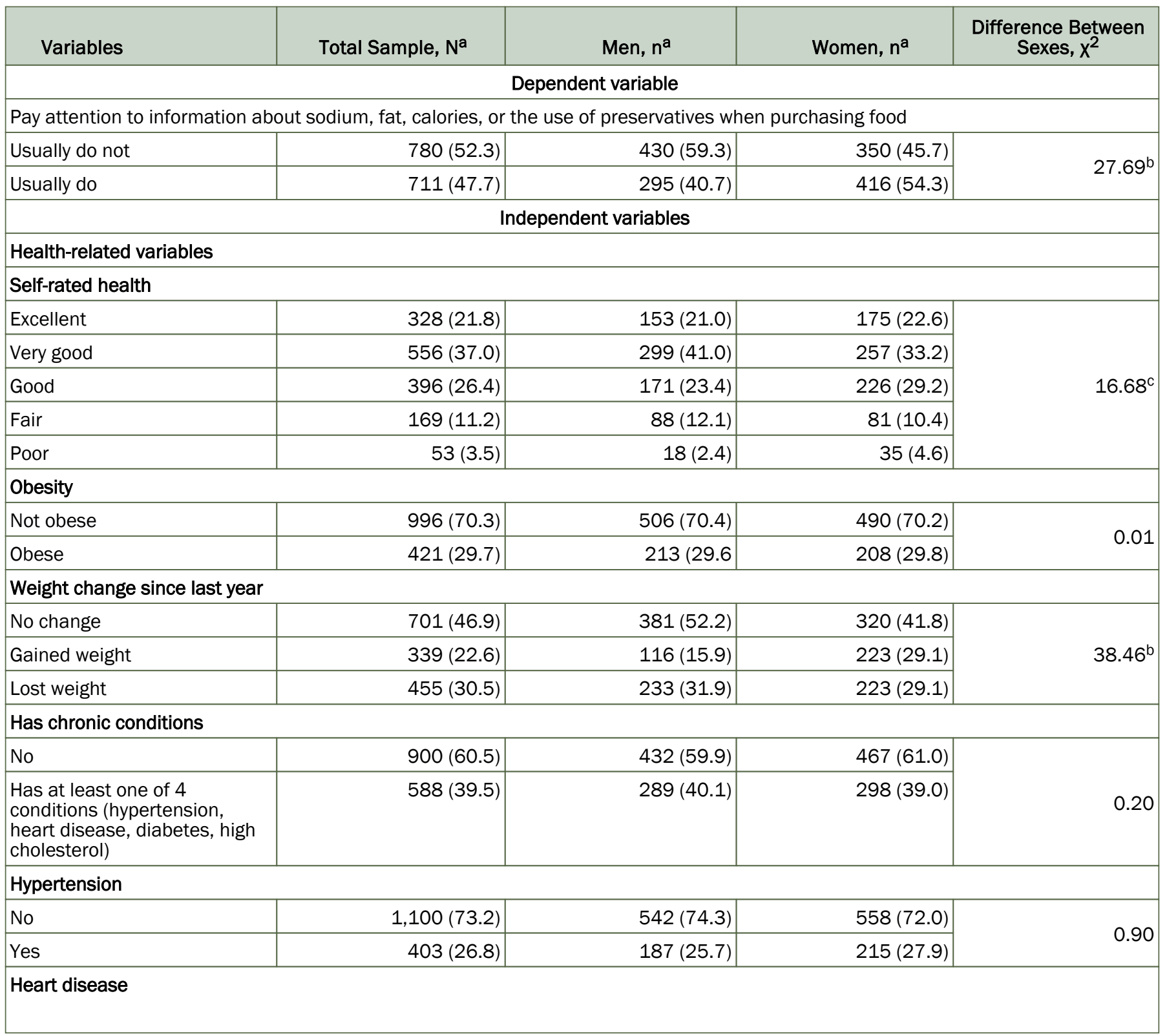

Abbreviation: SD, standard deviation; -, not applicable.

a Values in parentheses are means unless otherwise indicated.

b $P<.001$.

${ }^{c} P<.01$

d $P<.10$.

${ }^{\mathrm{e}}$ For difference between the sexes, $t=1.23$.

${ }^{f}$ For difference between the sexes, $t=6.05, P<.001$. 
(continued)

Table 1. Variables Used in Analysis of Nutrition Label Use and Health in a Sample $(\mathrm{N}=1,503)$ of Men and Women, Douglas County, Nebraska, 2013

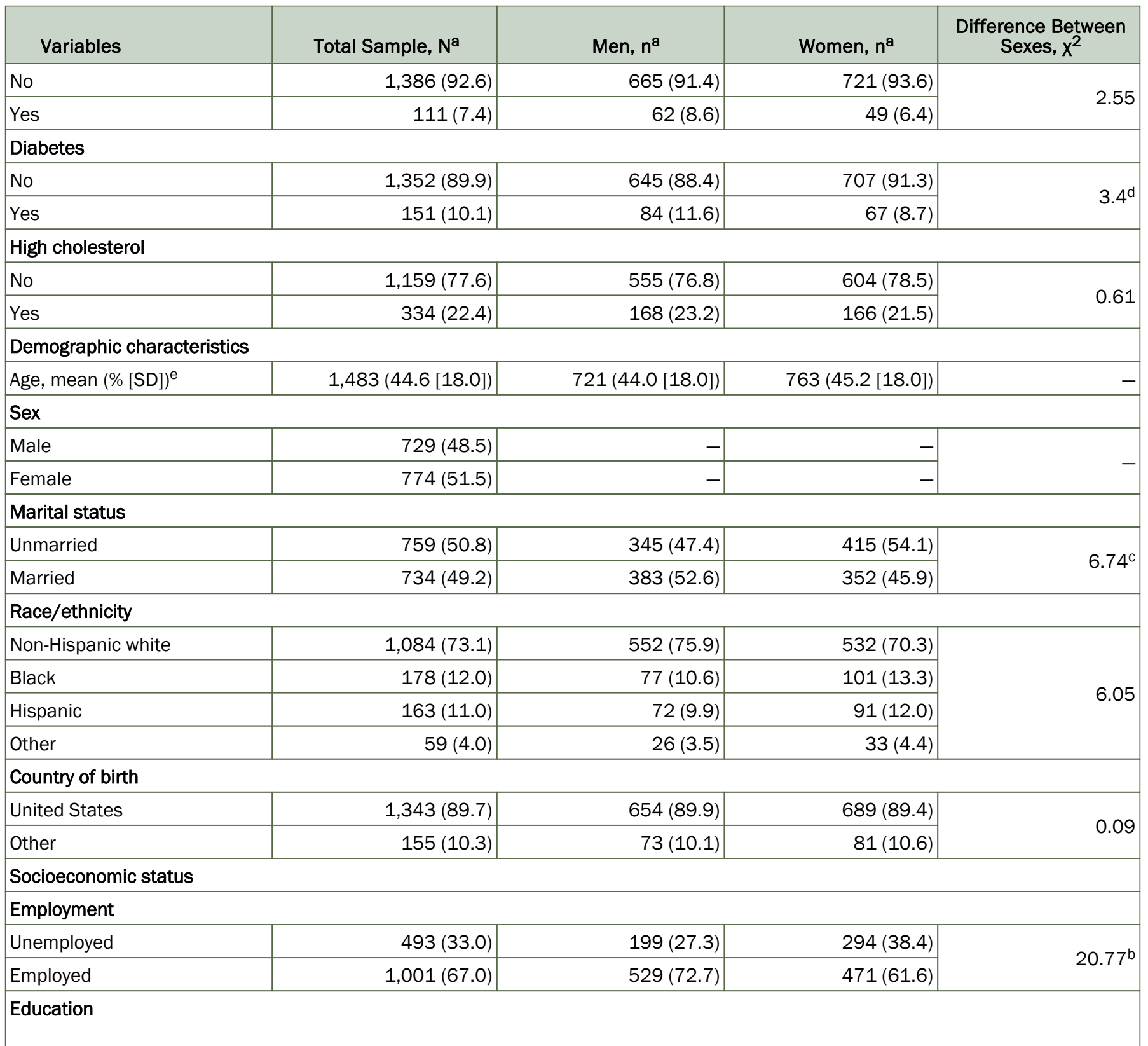

Abbreviation: SD, standard deviation; -, not applicable.

${ }^{a}$ Values in parentheses are means unless otherwise indicated.

b $P<.001$.

${ }^{c} P<.01$.

d $P<.10$.

e For difference between the sexes, $t=1.23$.

${ }^{f}$ For difference between the sexes, $t=6.05, P<.001$. 
(continued)

Table 1. Variables Used in Analysis of Nutrition Label Use and Health in a Sample $(\mathrm{N}=1,503)$ of Men and Women, Douglas County, Nebraska, 2013

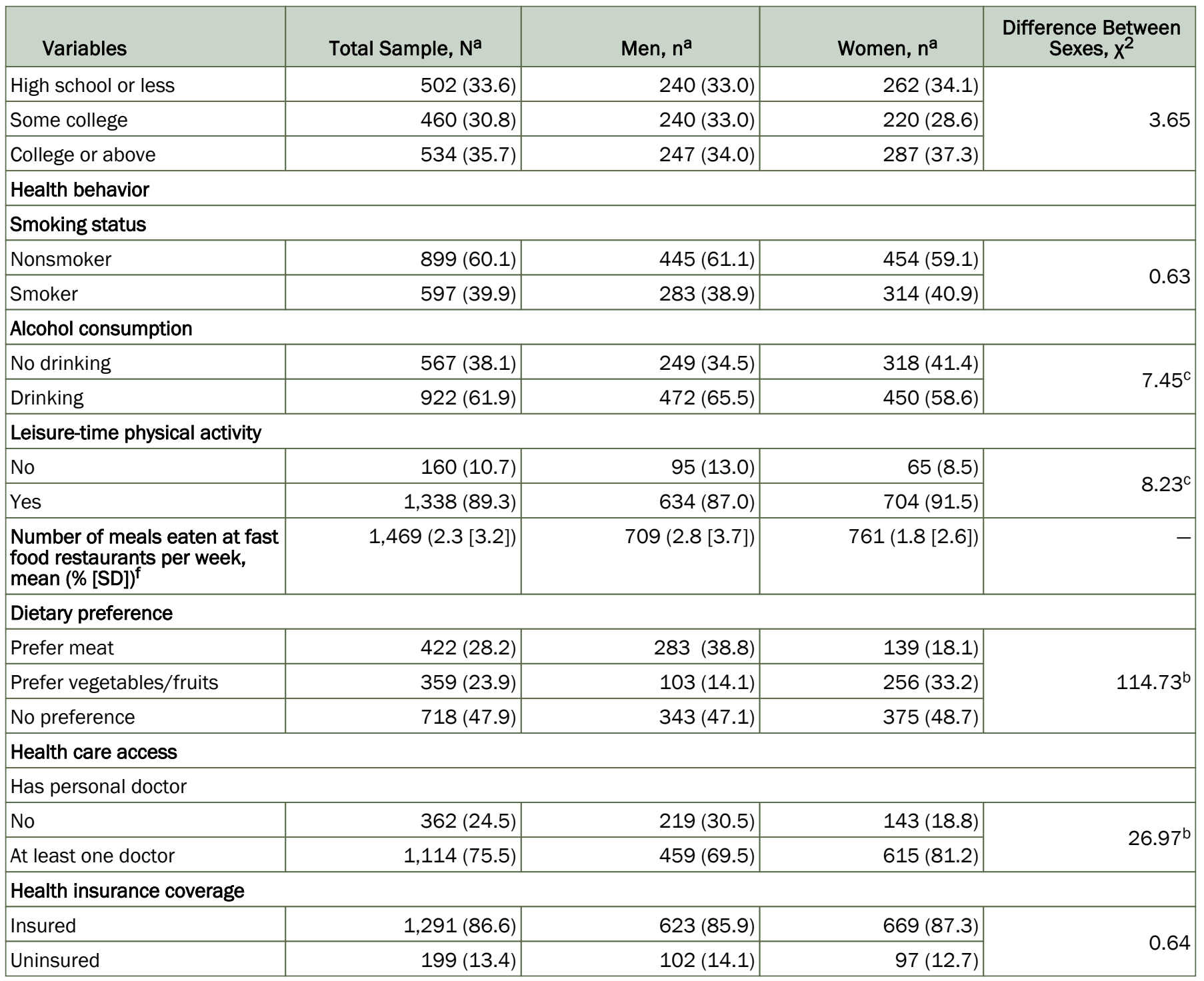

Abbreviation: SD, standard deviation; -, not applicable.

a values in parentheses are means unless otherwise indicated.

b $P<.001$

c $P<.01$.

d $P<.10$.

e For difference between the sexes, $t=1.23$.

For difference between the sexes, $t=6.05, P<.001$.

The opinions expressed by authors contributing to this journal do not necessarily reflect the opinions of the U.S. Department of Health and Human Services, the Public Health Service, the Centers for Disease Control and Prevention, or the authors' affiliated institutions. 
Table 2. Bivariate Associations Between Nutrition Label Use and Selected Health Indicators Among Sample $(N=1,503)$ of Men and Women, Douglas County, Nebraska, 2013

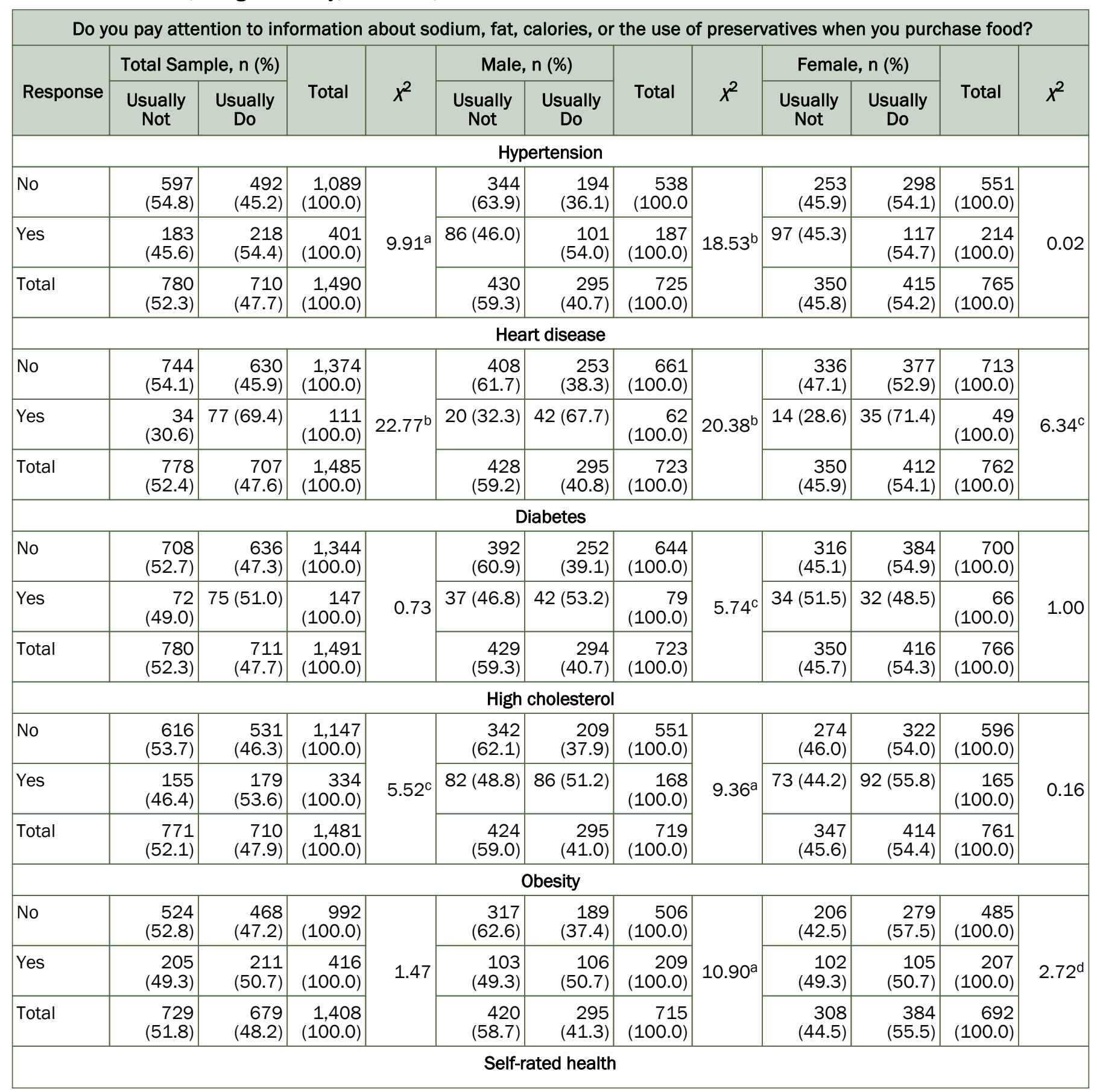

\footnotetext{
a $P<.01$

b $P<.001$.

${ }^{c} P<.05$
}

$\mathrm{d} P<.10$

(continued on next page)

The opinions expressed by authors contributing to this journal do not necessarily reflect the opinions of the U.S. Department of Health and Human Services, the Public Health Service, the Centers for Disease Control and Prevention, or the authors' affiliated institutions. 
(continued)

Table 2. Bivariate Associations Between Nutrition Label Use and Selected Health Indicators Among Sample $(N=1,503)$ of Men and Women, Douglas County, Nebraska, 2013

\begin{tabular}{|c|c|c|c|c|c|c|c|c|c|c|c|c|}
\hline \multicolumn{13}{|c|}{ Do you pay attention to information about sodium, fat, calories, or the use of preservatives when you purchase food? } \\
\hline Response & $\begin{array}{l}\text { Usually } \\
\text { Not }\end{array}$ & $\begin{array}{c}\text { Usually } \\
\text { Do }\end{array}$ & Total & $x^{2}$ & $\begin{array}{l}\text { Usually } \\
\text { Not }\end{array}$ & $\begin{array}{c}\text { Usually } \\
\text { Do }\end{array}$ & Total & $x^{2}$ & $\begin{array}{l}\text { Usually } \\
\text { Not }\end{array}$ & $\begin{array}{c}\text { Usually } \\
\text { Do }\end{array}$ & Total & $x^{2}$ \\
\hline Excellent & $\begin{array}{r}132 \\
(40.2)\end{array}$ & $\begin{array}{r}196 \\
(59.8)\end{array}$ & $\begin{array}{r}328 \\
(100.0) \\
\end{array}$ & \multirow{4}{*}{$63.23^{b}$} & $74(48.4)$ & 79 (51.6) & $\begin{array}{r}153 \\
(100.0) \\
\end{array}$ & \multirow{4}{*}{$23.27^{b}$} & $58(33.1)$ & $\begin{array}{r}117 \\
(66.9) \\
\end{array}$ & $\begin{array}{r}175 \\
(100.0) \\
\end{array}$ & \multirow{4}{*}{$63.20^{k}$} \\
\hline Good & $\begin{array}{r}226 \\
(57.4) \\
\end{array}$ & $\begin{array}{r}168 \\
(42.6) \\
\end{array}$ & $\begin{array}{r}394 \\
(100.0) \\
\end{array}$ & & $\begin{array}{r}103 \\
(60.2) \\
\end{array}$ & 68 (39.8) & $\begin{array}{r}171 \\
(100.0) \\
\end{array}$ & & $\begin{array}{r}123 \\
(55.2) \\
\end{array}$ & $\begin{array}{r}100 \\
(44.8) \\
\end{array}$ & $\begin{array}{r}223 \\
(100.0) \\
\end{array}$ & \\
\hline Fair & $\begin{array}{r}115 \\
(71.4) \\
\end{array}$ & 46 (28.6) & $\begin{array}{r}161 \\
(100.0)\end{array}$ & & $55(65.5)$ & 29 (34.5) & $\begin{array}{r}84 \\
(100.0) \\
\end{array}$ & & $61(78.2)$ & $17(21.8)$ & $\begin{array}{r}78 \\
(100.0)\end{array}$ & \\
\hline Poor & $\begin{array}{r}13 \\
(24.5)\end{array}$ & $40(75.5)$ & $\begin{array}{r}53 \\
(100.0)\end{array}$ & & $4(22.2)$ & $14(77.8)$ & $\begin{array}{r}18 \\
(100.0)\end{array}$ & & $9(25.7)$ & $26(74.3)$ & $\begin{array}{r}35 \\
(100.0)\end{array}$ & \\
\hline \multicolumn{13}{|c|}{ Weight change } \\
\hline No change & $\begin{array}{r}425 \\
(60.7)\end{array}$ & $\begin{array}{r}275 \\
(39.3)\end{array}$ & $\begin{array}{r}700 \\
(100.0)\end{array}$ & \multirow{4}{*}{$47.16^{b}$} & $\begin{array}{r}251 \\
(65.9)\end{array}$ & $\begin{array}{r}130 \\
(34.1)\end{array}$ & $\begin{array}{r}381 \\
(100.0)\end{array}$ & \multirow{4}{*}{$20.39^{b}$} & $\begin{array}{r}174 \\
(54.5)\end{array}$ & $\begin{array}{r}145 \\
(45.5)\end{array}$ & $\begin{array}{r}319 \\
(100.0)\end{array}$ & \multirow{4}{*}{$26.71^{\mathrm{b}}$} \\
\hline $\begin{array}{l}\text { Gained } \\
\text { weight }\end{array}$ & $\begin{array}{r}175 \\
(52.1)\end{array}$ & $\begin{array}{r}161 \\
(47.9)\end{array}$ & $\begin{array}{r}336 \\
(100.0)\end{array}$ & & 70 (60.9) & 45 (39.1) & $\begin{array}{r}115 \\
(100.0)\end{array}$ & & $\begin{array}{r}105 \\
(47.5)\end{array}$ & $\begin{array}{r}116 \\
(52.5)\end{array}$ & $\begin{array}{r}221 \\
(100.0)\end{array}$ & \\
\hline $\begin{array}{l}\text { Lost } \\
\text { weight }\end{array}$ & $\begin{array}{r}180 \\
(40.0)\end{array}$ & $\begin{array}{r}270 \\
(60.0)\end{array}$ & $\begin{array}{r}450 \\
(100.0)\end{array}$ & & $\begin{array}{r}108 \\
(47.4)\end{array}$ & $\begin{array}{r}120 \\
(52.6)\end{array}$ & $\begin{array}{r}228 \\
(100.0)\end{array}$ & & 71 (32.1) & $\begin{array}{r}150 \\
(67.9)\end{array}$ & $\begin{array}{r}221 \\
(100.0) \\
\end{array}$ & \\
\hline Total & $\begin{array}{r}780 \\
(52.5)\end{array}$ & $\begin{array}{r}706 \\
(47.5)\end{array}$ & $\begin{array}{r}1,486 \\
(100.0)\end{array}$ & & $\begin{array}{r}429 \\
(59.3)\end{array}$ & $\begin{array}{r}295 \\
(40.7)\end{array}$ & $\begin{array}{r}724 \\
(100.0)\end{array}$ & & $\begin{array}{r}350 \\
(46.0)\end{array}$ & $\begin{array}{r}411 \\
(54.0)\end{array}$ & $\begin{array}{r}761 \\
(100.0)\end{array}$ & \\
\hline
\end{tabular}

\footnotetext{
a $P<.01$

b $P<.001$

c $P<.05$

$\mathrm{d} P<.10$
} 
Table 3. Multivariate Logistic Regression on Nutrition Label Use Among Sample $(\mathrm{N}=1,503)$ of Men and Women, Douglas County, Nebraska, 2013

\begin{tabular}{|c|c|c|c|}
\hline \multirow[b]{2}{*}{ Variable } & Total Sample $(n=1,253)$ & Male $(n=539)$ & Female $(n=714)$ \\
\hline & \multicolumn{3}{|c|}{ Odds Ratio (95\% Cl) } \\
\hline \multicolumn{4}{|c|}{ Health-related variables } \\
\hline \multicolumn{4}{|l|}{ Self-rated health } \\
\hline Excellent & \multicolumn{3}{|c|}{1 [Reference] } \\
\hline Very good & $0.58^{\mathrm{a}}(0.41-0.81)$ & $0.46^{\mathrm{a}}(0.28-0.74)$ & $0.72(0.43-1.22)$ \\
\hline Good & $0.56^{\mathrm{a}}(0.38-0.82)$ & $0.40^{\mathrm{a}}(0.22-0.72)$ & $0.69(0.39-1.21)$ \\
\hline Fair & $0.22^{\mathrm{b}}(0.13-0.38)$ & $0.56(0.27-1.17)$ & $0.06^{b}(0.03-0.16)$ \\
\hline Poor & $2.16^{\mathrm{C}}(0.90-5.18)$ & $3.47^{\mathrm{C}}(0.88-13.70)$ & $1.59(0.46-5.52)$ \\
\hline \multicolumn{4}{|l|}{ Obesity } \\
\hline No & \multicolumn{3}{|c|}{1 [Reference] } \\
\hline Obese & $1.81^{\mathrm{b}}(1.33-2.46)$ & $2.63^{\mathrm{b}}(1.69-4.09)$ & $1.28(0.79-2.05)$ \\
\hline \multicolumn{4}{|l|}{ Weight change since last year } \\
\hline No change & \multicolumn{3}{|c|}{1 [Reference] } \\
\hline Gained weight & $1.69^{\mathrm{a}}(1.22-2.34)$ & $1.41(0.84-2.39)$ & $2.78^{b}(1.72-4.48)$ \\
\hline Lost weight & $2.72^{\mathrm{b}}(2.02-3.67)$ & $2.55^{\mathrm{b}}(1.68-3.87)$ & $3.87^{b}(2.37-6.31)$ \\
\hline \multicolumn{4}{|l|}{ Has chronic conditions } \\
\hline No & \multicolumn{3}{|c|}{1 [Reference] } \\
\hline $\begin{array}{l}\text { Has at least } 1 \text { of } 4 \text { conditions } \\
\text { (hypertension, heart disease, } \\
\text { diabetes, high cholesterol) }\end{array}$ & $1.21(0.88-1.66)$ & $1.71^{\mathrm{d}}(1.10-2.66)$ & $0.94(0.56-1.58)$ \\
\hline \multicolumn{4}{|c|}{ Demographics } \\
\hline Age & $1.01^{\mathrm{a}}(1.00-1.02)$ & $1.01(0.99-1.02)$ & $1.02^{\mathrm{a}}(1.01-1.04)$ \\
\hline \multicolumn{4}{|l|}{ Sex } \\
\hline Male & \multicolumn{3}{|c|}{1 [Reference] } \\
\hline Female & $1.14(0.87-1.49)$ & - & - \\
\hline \multicolumn{4}{|l|}{ Marital status } \\
\hline Unmarried & \multicolumn{3}{|c|}{1 [Reference] } \\
\hline Married & $1.42^{\mathrm{d}}(1.07-1.88)$ & $1.25(0.82-1.92)$ & $1.59^{d}(1.04-2.44)$ \\
\hline \multicolumn{4}{|l|}{ Race/ethnicity } \\
\hline Non-Hispanic white & \multicolumn{3}{|c|}{1 [Reference] } \\
\hline Black & $1.20(0.78-1.84)$ & $1.39(0.72-2.71)$ & $1.40(0.74-2.65)$ \\
\hline Hispanic & $1.36(0.79-2.32)$ & $0.82(0.35-1.91)$ & $1.61(0.74-3.54)$ \\
\hline Other & $1.95^{\mathrm{C}}(0.97-3.90)$ & $1.76(0.62-5.06)$ & $3.48^{d}(1.21-10.05)$ \\
\hline
\end{tabular}

Abbreviations: $\mathrm{Cl}$, confidence interval; -, not applicable.

a $P<.01$.

$\mathrm{b} P<.001$

c $P<.10$.

d $P<.05$. 
(continued)

Table 3. Multivariate Logistic Regression on Nutrition Label Use Among Sample $(\mathrm{N}=1,503)$ of Men and Women, Douglas County, Nebraska, 2013

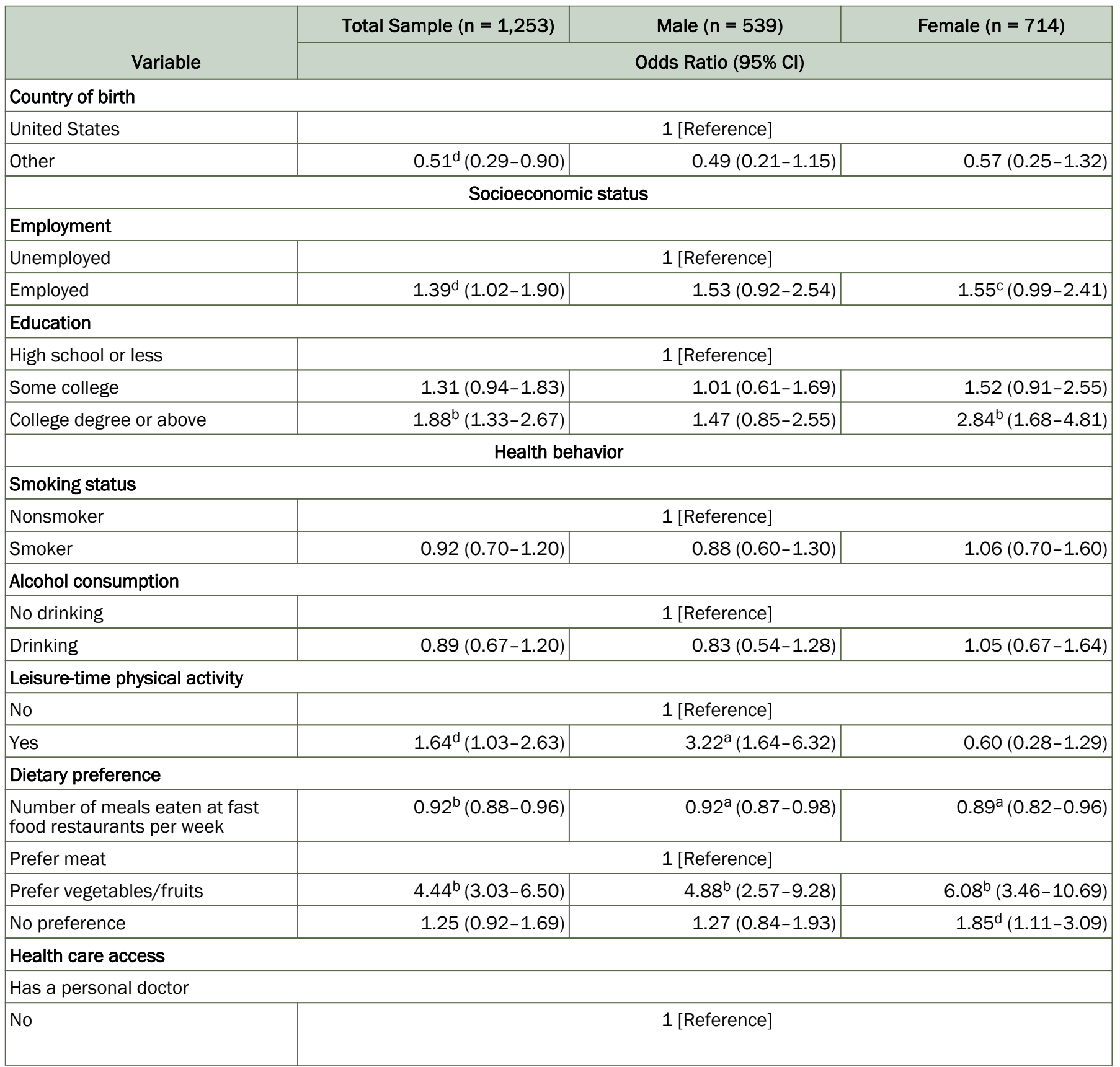

Abbreviations: $\mathrm{Cl}$, confidence interval; -, not applicable.

a $P<.01$.

b $P<.001$.

c $P<.10$.

d $P<.05$. the Public Health Service, the Centers for Disease Control and Prevention, or the authors' affiliated institutions. 
(continued)

Table 3. Multivariate Logistic Regression on Nutrition Label Use Among Sample $(\mathrm{N}=1,503)$ of Men and Women, Douglas County, Nebraska, 2013

\begin{tabular}{|c|c|c|c|}
\hline & Total Sample $(n=1,253)$ & Male $(n=539)$ & Female $(n=714)$ \\
\hline Variable & \multicolumn{3}{|c|}{ Odds Ratio (95\% Cl) } \\
\hline At least one doctor & $1.18(0.83-1.66)$ & $1.85^{d}(1.14-3.02)$ & $0.74(0.42-1.30)$ \\
\hline \multicolumn{4}{|l|}{ Health insurance coverage } \\
\hline Insured & \multicolumn{3}{|c|}{1 [Reference] } \\
\hline Uninsured & $0.95(0.61-1.48)$ & $1.48(0.79-2.78)$ & $0.85(0.41-1.78)$ \\
\hline
\end{tabular}

Abbreviations: $\mathrm{Cl}$, confidence interval; -, not applicable.

a $P<.01$.

${ }^{\mathrm{b}} P<.001$

c $P<.10$.

d $P<.05$. 